\title{
WILHELM WUNDT: ZUR LAGE
}

\begin{abstract}
Unter dem bekannten Aufruf des Unabhängingen Ausschusses zum deutschen Frieden, gegen den wir gezwungen waren Einspruch zu erheben (Poln. Bl. Nr. 34) befand sich auch der Name Wilhelm Wundts. Um Aufklärung über die Stellungnahme des grossen Gelehrten zur polnischen Frage zu erlangen, richteten wir an ihn ein diesbezügliches Schreiben. Darauf hatte Se. Exzellenz, der verehrte Verfasser, die Freundlichkeit, uns folgende Antwort zuzusenden, die wir mit seiner Genehmigung der Öffentlichkeit übermitteln.
\end{abstract}

Schriftleitung der „Polnischen Blätter“.

Heidelberg, 22. September 1916 Plöck 48.

Hochgeehrter Herr!

Indem ich Ihnen für die freundliche Uebersendung der beiden Hefte der „Polnischen Blätter”, die ich von Leipzig aus erhalten habe, bestens danke, glaube ich Ihnen versichern zu können, dass sich meine Anschauungen über unser künftiges Verhältnis zu Polen nicht verändert haben. Ich bin, wie im Anfang des Krieges, heute noch der Ueberzeugung, dass es sich um eine Annexion Polens nimmermehr handeln könne, sondern dass nur ein autonomes, aber allerdings in gesicherter Verbindung mit den Zentralmächten bleibendes Polen den Opfern entspreche, mit denen die Zentralmächte diese Autonomie errungen haben. Wie solche Garantien zu gewinnen und die möglichen Gefahren, die ein autonomer polnischer Staat an unserer Ostgrenze in einer ferneren Zukunft mit sich führen könnte, zu vermeiden seien, darin liegt aber allerdings die große Schwierigkeit der polnischen Frage. Was wir jetzt schon sicher wissen, ist nur, dass wir ein polnisches Reich als Glied des deutschen Reiches nicht brauchen können, dass es uns dagegen als treu verbündeter Staat, als Schutzwehr zugleich gegen die auch nach dem Frieden bleibende russische Gefahr in hohem Grade wertvoll sein kann. Es lag namentlich zu Anfang des Krieges gewiss am nächsten zu denken, dass die österreichisch-ungarische Monarchie am ehesten die geeignete Form einer freieren Angliederung, etwa nach dem Muster der beiden schon bestehenden Hälften dieses Reichs, bieten werde. Ob sich aber diese 
Annahme jetzt und vollends zu Ende des Krieges halten lässt, und namentlich ob die österreichische Staatsleitung selbst einer solchen Lösung des Problems zugeneigt sein wird, darüber muss ich mich des Urteils enthalten. Sicher bleibt nur, dass hier ein Weg gefunden werden muss. Die von Ihnen erwähnte Stellung in dem Aufruf des Unabhängigen Ausschusses habe ich meinerseits nur in diesem Sinne aufgefasst, dabei aber als eine nebensächliche Aeusserung betrachtet, die hier ganz gegen die Hauptsache zurücktrat, und diese Hauptsache bestand für mich in der entschiedenen Betonung der Forderung, die in dem Aufruf des nationalen Ausschusses nicht zur gebührenden Geltung kam. Dies ist die durch die Gefahren des immer mehr in den Vordergrund tretenden Wirtschaftskrieges wahrlich vor allem dringend gewordenen Niederkämpfung Englands, das nach meiner Auffassung zur höchsten Gefahr nicht nur für Deutschland, sondern für ganz Europa, ja für die Welt geworden ist durch die rücksichtslose Gewalttätigkeit, mit der es diesen Krieg durch alle Mittel der Aushungerung, die ihm zu Gebote stehen, zur Entscheidung zu bringen sucht.

Indem ich nicht bezweifle, dass Sie diesen Gesichtspunkten ihre Berechtigung nicht bestreiten werden, verbleibe ich

in grösster Hochachtung ihr ergebener W. Wundt. 
(6) porwin

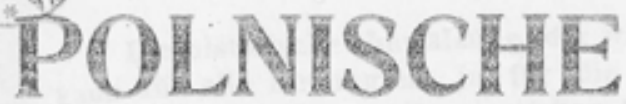

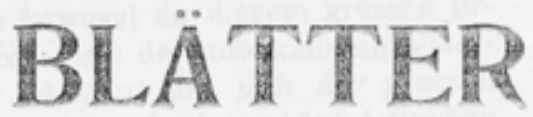

Zeitschrift für Politik, Kultur und soziales Leben.

Herausgeber: W. Feldman.

\title{
Band V
}

(Oktober-Dezember 1916).

\author{
Berlin-Charlottenburg \\ Verlag der ,Polnischen Blätter" \\ Sehlateratr. 28,
}

